\title{
Intrauterine Neospora caninum inoculation of heifers
}

\author{
E. Serrano $^{\text {a }}$, I. Ferre ${ }^{\text {a }}$, K. Osoro ${ }^{\text {b }}$, G. Aduriz ${ }^{\text {c }}$, A. Mateos-Sanz $^{\text {a }}$, A. Martínez $^{\text {b }}$, \\ R. Atxaerandio ${ }^{c}$, C.O. Hidalgo ${ }^{\mathrm{d}}$, L.M. Ortega-Mora ${ }^{\mathrm{a}, *}$ \\ ${ }^{a}$ Departamento de Sanidad Animal, Facultad de Veterinaria, Universidad Complutense de Madrid, \\ Ciudad Universitaria s/n, E-28040 Madrid, Spain \\ b Área de Sistemas de Producción Animal, Servicio Regional de Investigación y Desarrollo Agroalimentario (SERIDA), \\ Consejería de Medio Rural y Pesca, Asturias, E-33300 Villaviciosa, Spain \\ ${ }^{\mathrm{c}}$ Departamento de Sanidad Animal, Instituto Vasco de Investigación y Desarrollo Agrario (NEIKER), \\ Berreaga 1, E-48160 Derio, Bizkaia, Spain \\ dÁrea de Selección y Reproducción Animal, Servicio Regional de Investigación y Desarrollo Agroalimentario (SERIDA) \\ Consejería de Medio Rural y Pesca, Asturias, E-33202 Gijón, Spain
}

Received 31 May 2005; received in revised form 19 September 2005; accepted 6 October 2005

\begin{abstract}
Here, we studied the potential of Neospora caninum tachyzoites to infect heifers when administered in utero by artificial insemination via contaminated semen. Eighteen primiparous cyclic heifers were hormonally synchronized and artificially inseminated. Nine of them, which were inseminated with semen containing $10^{7}$ live $N$. caninum NC-1 isolate-tachyzoites, reacted with seroconversion and a specific IFN- $\gamma$ response. Moreover, $N$. caninum DNA was demonstrated by a nested-PCR in the blood of all nine heifers and in brain, lungs, liver and uterine horn of several of them. In contrast, nine heifers inseminated with tachyzoite-free semen developed no antibody or IFN- $\gamma$ responses, and no parasite DNA was detected in blood or organs. At necropsy, viable embryos were detected in one and six of the infected and non-infected heifers, respectively. No specific Neospora DNA was detected in any of the embryos. This study provides evidence that intrauterine inoculation via contaminated semen cause $N$. caninum infection in cattle.
\end{abstract}

(C) 2005 Elsevier B.V. All rights reserved.

Keywords: Neospora caninum; Intrauterine inoculation; Transmission; Heifers; Semen

\section{Introduction}

Neospora caninum is a heteroxenous cyst-forming apicomplexan, which has emerged as an important

\footnotetext{
* Corresponding author. Tel.: +34 91 3944069; fax: +34913943844.

E-mail address: luis.ortega@ vet.ucm.es (L.M. Ortega-Mora).
}

cause of reproductive failure in cattle worldwide (Dubey, 2003). In the Neospora life cycle, dogs (McAllister et al., 1998) and coyotes (Gondim et al., 2004) are both intermediate and definitive hosts; cattle and other mammals are natural intermediate hosts (Dubey, 2003). Cattle are generally infected prenatally by transplacental infection from persistently infected dams (Paré et al., 1996; Davison et al., 1999). Other 
possible postnatal sources of vertical transmission, such as colostrum or milk, have not yet been confirmed in naturally infected cattle (Uggla et al., 1998). Epidemiological evidence also suggests horizontal transmission (Davison et al., 1999; Dijkstra et al., 2001). Calves (De-Marez et al., 1999) and pregnant cows (Trees et al., 2002) can be experimentally infected by Neospora oocyst shedding by dogs when administered orally. In addition, $N$. caninum life cycle has been reproduced by cyclical oral transmission between dogs and cattle (Gondim et al., 2002). $N$. caninum DNA was recently reported in fresh and frozen semen from naturally infected bulls (OrtegaMora et al., 2003; Caetano-da-Silva et al., 2004; Ferre et al., 2005), and the possibility of venereal transmission has been suggested in bovine neosporosis.

Here, we studied the potential of $N$. caninum tachyzoites to infect heifers when administered in utero by artificial insemination (AI) using experimentally contaminated semen.

\section{Materials and methods}

\subsection{Heifers}

Eighteen primiparous cyclic heifers of the Asturiana de los Valles breed, aged between 25 and 35 (median 27) months and live weights from 350 to $576 \mathrm{~kg}$ (median 430) were included in the study. Prior to experiment started, blood samples were taken from all 18 heifers and tested for evidence of exposure to bovine viral diarrhoea virus, infectious bovine rhinotracheitis virus, Leptospira hardjo and Brucella abortus (assays conducted by the Instituto Vasco de Investigación y Desarrollo Agrario, NEIKER, Derio, Spain). The heifers were negative for all four abortifacient agents. Heifers were also tested twice by ELISA (CIVTEST, Hipra Laboratories S.A., Girona, Spain) for evidence of $N$. caninum exposure, and were always seronegative.

\subsection{Experimental design}

Heifers were randomly allocated in two groups (A and B) of nine animals each, and housed in the same pen for the duration of the experiment. The heifers were isolated from other livestock in SERIDA facilities (Finca "La Mata", Grado, Asturias; Servicio Regional de Investigación y Desarrollo Agroalimentario del Principado de Asturias, Spain), and were fed with straw and a commercial cattle concentrate. All 18 cyclic heifers were synchronized hormonally with two doses of a synthetic PGF2 $\alpha$ analogue given 11 days apart $(2 \mathrm{ml}$ i.m., Prosolvin, Intervet, Salamanca, Spain). Oestrus detection (day 0; 2.5 days after the second PGF2 $\alpha$ analogue administration on average) was based on monitoring of behavioural signs three times daily and serum progesterone levels. Heifers were artificially inseminated using standard techniques on day 1 to produce synchronous pregnancies. Semen from a bull of the Asturiana de los Valles breed that did not show specific serum antibodies to $N$. caninum by repeated ELISA (CIVTEST) was used for AI. Group A was inseminated with semen contaminated with $10^{7} \mathrm{~N}$. caninum tachyzoites and group B was inseminated with the same, tachyzoite-free semen as control. The experiment was conducted between November and December 2003, and the heifers were monitored daily for 35 days post-insemination. Rectal temperatures of all animals were recorded before insemination and twice daily thereafter. Animals with temperatures above $39.5^{\circ} \mathrm{C}$ were considered to be febrile.

\subsection{Parasite inoculum}

Tachyzoites used to contaminate semen in the experimental infections were obtained from MARC145 cell monolayer cultures of the $N$. caninum NC-1 isolate. Briefly, cells were maintained in Dulbecco's modified Eagle medium supplemented with 10\% foetal bovine serum, $15 \mathrm{mM} \mathrm{N}$-2-hydroxyethylpiperazine- $N^{\prime}$-2-ethane-sulfonic acid (pH 7.2), $2 \mathrm{mM}$ glutamine, $100 \mathrm{U} / \mathrm{ml}$ penicillin, $100 \mu \mathrm{g} / \mathrm{ml}$ streptomycin and $250 \mathrm{ng} / \mathrm{ml}$ fungizone, and incubated $\left(37{ }^{\circ} \mathrm{C}, 5 \% \mathrm{CO}_{2}\right)$. Cells were passaged twice weekly. Tachyzoites were maintained by serial passage on MARC-145 monolayers at a 1:1 host-parasite ratio, and were harvested from monolayers after 4 days culture by scraping the parasite-infected cell monolayer using a sterile cell scraper. Cells were washed three times in sterile $0.3 \mathrm{M}$ phosphate-buffered saline (PBS, pH 7.4) and separated from host cell debris by passing the mixture through a 25 -gauge needle after passage through a $5-\mu \mathrm{m}$ polycarbonate filter. 
Tachyzoites were counted in a haemocytometer and resuspended in PBS. Tachyzoites $\left(10^{7}\right)$ were diluted in $250 \mu \mathrm{l}$ of PBS and added to $250 \mu \mathrm{l}$ of semen and packed in $500 \mu \mathrm{l}$ AI straws, which were transported in an insulated box $\left(37^{\circ} \mathrm{C}\right)$ to the animal house for use. Parasites were administered to heifers within $30 \mathrm{~min}$ of harvest from tissue culture. On day 0 , each of the nine heifers in group A were inseminated with $500 \mu \mathrm{l}$ of diluted semen containing $10^{7}$ live tachyzoites of the $N$. caninum $\mathrm{NC}-1$ isolate; each of the nine heifers in group B were inseminated with $250 \mu$ l of tachyzoitefree semen plus $250 \mu \mathrm{l}$ of PBS.

\subsection{Samples and procedures}

Blood samples were collected by coccygeal venipuncture in EDTA, plain and heparinized tubes for DNA extraction, serological and IFN- $\gamma$ analysis, respectively. Parasitaemia and serology were analysed three times before insemination and three times a week thereafter, until 35 days post-insemination.

Serum samples were assayed for specific IgG antibodies using a commercial kit (CIVTEST) as recommended by the manufacturer, with positive and negative controls. Commercial plates coated with $N$. caninum soluble antigen (CIVTEST) were used to assay serum samples for other immunoglobulin isotypes. Anti-IgG1, IgG2 and IgM conjugates were purchased from Serotec (Oxford, UK). The optimal concentration of each conjugate was determined by checkerboard titration (IgG1, 1/100,000; IgG2, 1/ 40,000; IgM, 1/150,000) using positive and negative serum samples. ELISA was performed following manufacturer's recommendations, using tetramethylbenzidine substrate (Sigma, USA). Test results were expressed as optical density (OD) values.

To assess IFN- $\gamma$ production, duplicate aliquots of heparinized blood $(900 \mu \mathrm{l})$ from each heifer were transferred into each of three wells of 24-well tissue culture plates (Soria Greiner, Spain) and cultured with $100 \mu \mathrm{l}$ of PBS (unstimulated control), concanavalin A $(10 \mu \mathrm{g} / \mathrm{ml}$; Sigma) to ensure the ability of the cells to respond to stimulation and secrete IFN- $\gamma$, and with $N$. caninum NC-1 strain soluble antigen. Optimal antigen concentration $(1 \mu \mathrm{g} / \mathrm{ml})$, and remaining assay parameters were determined previously by checkerboard titration using blood from a strongly seropositive heifer (not shown). Cultures were incubated (16 h, $\left.37{ }^{\circ} \mathrm{C}, 5 \% \mathrm{CO}_{2}\right)$. Plates were centrifuged $(500 \times g$, $10 \mathrm{~min}$ ), plasma was harvested from each well and frozen at $-20{ }^{\circ} \mathrm{C}$ until testing. Duplicate plasma samples were tested for IFN- $\gamma$ production by ELISA (Bovigam IFN- $\gamma$ kit, CSL, Australia) following manufacturer's recommendations. Test results were expressed as optical density (OD) values.

For parasitaemia studies, DNA was extracted from $500 \mu \mathrm{l}$ of EDTA-whole blood using a Genomic-Prep Blood DNA isolation kit (Amersham Biosciences Ltd., UK) following manufacturer's instructions. A previously described nested-PCR procedure (OrtegaMora et al., 2003) on the internal transcribed spacer (ITS1) region of $N$. caninum was used to detect the presence of Neospora DNA in blood. In each amplification, a DNA extraction and PCR controls equivalent to $10^{2}$ tachyzoites, respectively, were employed as positive controls. To identify false positive results, negative control reactions (reactions without template or reactions with DNA of $N$. caninum-negative blood) were added to each set of PCRs.

At 36 days post-insemination, heifers were sacrificed following EU standard legal procedures. Samples of brain (forebrain, midbrain and hindbrain), lungs (left lobe), liver, heart and genital tract (vagina, cervix, uterus, uterine horn, oviduct, ovary and embryos if presented) were collected aseptically for PCR analysis. The tissue samples taken were as generous as possible, and in the case of the larger available tissue masses (brain and lungs) the samples were sometimes as large as $10 \mathrm{~g}$. Samples were triplewrapped in sealable polythene bags and stored at $-80{ }^{\circ} \mathrm{C}$ for analysis. To optimise parasite DNA detection, tissue samples (1-4g) from different regions of each organ were homogenised and DNA was extracted from a $15 \mathrm{mg}$ subsample using a Genomic-Prep Tissue DNA isolation kit (Amersham Biosciences Ltd.) and replicate PCR reactions were carried out as above.

\subsection{Data analysis}

Rectal temperature, serological and IFN- $\gamma$ data were analysed using an independent two-sample $t$-test to compare infected and control groups. A $P$-value of less than 0.05 was taken to indicate that the values of the two treatments were not similar. 


\section{Results}

Infected heifers showed virtually no clinical symptoms and there was no significant difference between the groups when rectal temperature was compared (not shown). In group A heifers, significant serum specific IgG antibody responses to $N$. caninum were observed from 18 days p.i. (Fig. 1 a, $P<0.05$ ). Specific IgG1 and IgG2 serum levels were first detected 15 (Fig. 1b) and 18 (Fig. 1c) days p.i., respectively. Anti- $N$. caninum $\operatorname{IgG} 1$ and $\mathrm{IgG} 2$ levels were significantly different $(P<0.05)$ in infected heifers compared to uninfected controls by days 18 and 28, respectively. Anti- $N$. caninum IgM was detected 15 days p.i., but only was significantly different from controls at 25 days p.i. (not shown). In all nine infected heifers, overall antibody responses were similar in magnitude and kinetics. Serum specific IFN- $\boldsymbol{\gamma}$ responses in infected heifers were observed at 4 days p.i., but IFN- $\gamma$ levels decreased in all heifers afterwards (Fig. 1d). However, IFN- $\gamma$ levels in group A were higher than control group from 25 days p.i., but not significantly. Infection of group A heifers was also confirmed when $N$. caninum DNA was detected intermittently from days 12 to 21 p.i. in blood of all nine animals (Table 1) and in brain, left lung lobe, liver and left uterine horn of some of
Table 1

Detection of $N$. caninum DNA in blood of nine heifers experimentally infected with $10^{7}$ tachyzoites of NC-1 isolate via contaminated semen and monitored for 35 days

\begin{tabular}{lllllllll}
\hline Heifer number & \multicolumn{1}{l}{ Days } & \multicolumn{1}{l}{$l$} & & & & & \\
\cline { 2 - 8 } & $1-11$ & 12 & 13 & 14 & 15 & 18 & 21 & $22-35$ \\
\hline 511 & - & - & + & - & + & + & - & - \\
1205 & - & - & - & - & - & - & + & - \\
2098 & - & - & + & - & + & - & - & - \\
2456 & - & + & + & - & + & + & - & - \\
2433 & - & - & - & - & + & - & - & - \\
5507 & - & - & + & - & - & + & - & - \\
5746 & - & - & + & - & + & - & - & - \\
7983 & - & - & + & - & - & - & - & - \\
7989 & - & - & + & - & + & - & - & - \\
\hline
\end{tabular}

Parasite DNA in blood: - , PCR negative sample; + , PCR positive sample.

them (Table 2). Group B heifers did not develop serum specific antibody or IFN- $\gamma$ responses to $N$. caninum and no specific Neospora DNA was detected in their blood, brain, lungs, liver, heart and genital tract.

At necropsy, a viable embryo was found in one and six heifers of groups A and B, respectively. All embryos were similar in size and length and fell within expected stage of development. No specific Neospora DNA was detected in any of the embryos.

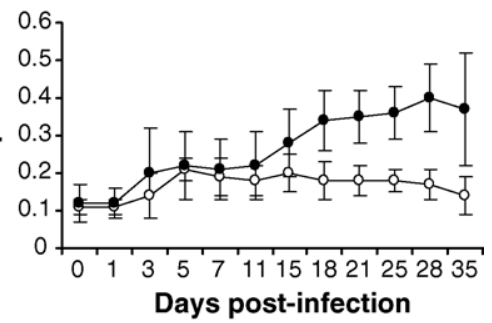

(a)

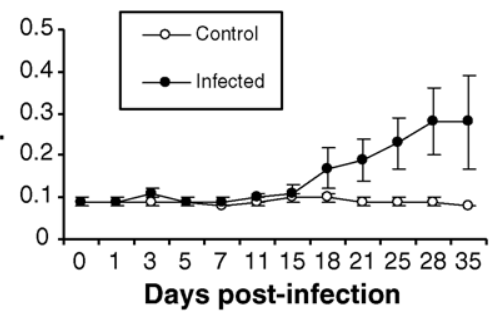

(b)

Days post-infection

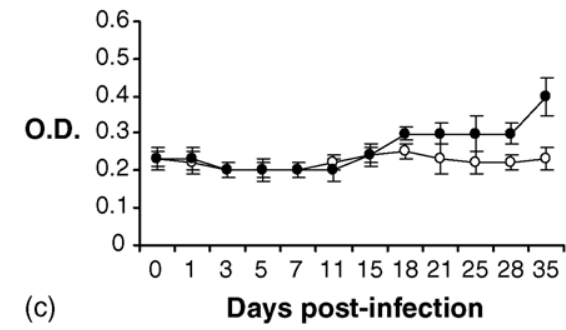

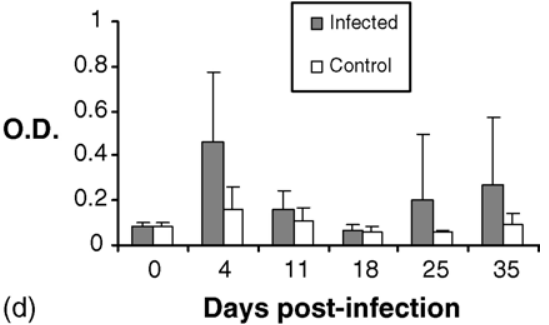

Fig. 1. Serum specific antibody and IFN- $\gamma$ responses in heifers experimentally infected with $10^{7}$ tachyzoites of $N$. caninum (NC-1 isolate) via contaminated semen: (a) IgG; (b) IgG1; (c) IgG2; (d) IFN- $\gamma$. Graphs show the mean \pm S.D. of nine infected (black) and nine control (white) heifers. 
Table 2

Detection of $N$. caninum DNA in tissues of nine heifers experimentally infected with $10^{7}$ tachyzoites of NC-1 isolate via contaminated semen and sacrificed at 36 days post-insemination

\begin{tabular}{|c|c|c|c|c|}
\hline \multirow[t]{2}{*}{ Heifer number } & \multicolumn{4}{|c|}{ Post-mortem examination } \\
\hline & Brain & Organs & Genital tract & Embryo \\
\hline 511 & + & - & $+($ left uterine horn) & ND \\
\hline 1205 & - & - & - & ND \\
\hline 2098 & + & - & - & ND \\
\hline 2456 & + & - & $+($ left uterine horn) & ND \\
\hline 2433 & - & + (liver) & - & ND \\
\hline 5507 & - & - & - & ND \\
\hline 5746 & - & - & - & - \\
\hline 7983 & - & $+($ left lung lobe $)$ & - & ND \\
\hline 7989 & + & - & - & ND \\
\hline
\end{tabular}

Parasite DNA in tissues: - , PCR negative sample; +, PCR positive sample. ND: not done.

\section{Discussion}

This study provides evidence that intrauterine inoculation via contaminated semen cause $N$. caninum infection in cattle. The nine heifers inseminated with semen containing $N$. caninum tachyzoites reacted with seroconversion and a specific IFN- $\gamma$ response, indicating exposure to parasite antigens. In addition, $N$. caninum DNA was detected by PCR in blood and some organs of infected heifers. Although the experiment was not performed under gnotobiotic conditions, we consider it unlikely that there was any other source of $N$. caninum infection in the nine heifers other than the inoculation performed. The nine heifers that remained seronegative were housed in the same pen and were fed the same fodder as the heifers that seroconverted. In addition, the intrauterine inoculation via contaminated semen of $N$. caninum tachyzoites could contribute to pregnancy losses during the embryonic period. Only one of the nine infected heifers was pregnant on day 36 postinsemination when the pregnancy rate in control group was $66.6 \%$.

The heifers which were seronegative to $N$. caninum prior to insemination seroconverted as early as 18 days p.i., while the uninfected control heifers remained seronegative throughout the study ( 35 days). The IgG responses recorded for each of the nine heifers were of significant magnitude and commenced at a similar time after the experimental infection. Antibody levels then increased, indicating active infection with ongoing antigenic stimulus due to an active infection. The general pattern of $\mathrm{IgG}$ responses was similar to those reported for calves (De-Marez et al., 1999; Maley et al., 2001) and pregnant cows (Andrianarivo et al., 2001; Trees et al., 2002) challenged with tachyzoites or oocysts, although in our experiment immune responses were assayed for a shorter period. Both experimental (Williams et al., 2000) and natural $N$. caninum infection (Guy et al., 2001; Ferre et al., 2005) induce a typical type 1 helper T cell response, characterised by high IFN- $\gamma$ levels and an IgG2 antibody response. It is likely that this response is involved in controlling tachyzoite multiplication. In our experiment, infected heifers showed a predominant $\mathrm{IgG} 1$ response until 35 days p.i. (IgG1//gG2 ratio was $>1$ from 5 to 28 days p.i.), coinciding with decreased IFN- $\gamma$ response from days 11 to 18 p.i. A definitive conclusion cannot be drawn, however, due to the short duration of the experiment, and since pregnancy hormones may modulate the immune response in bovine neosporosis (Innes et al., 2002). The positive PCR results in blood and some organs nonetheless demonstrate that infection was established in all nine infected heifers. The presence of parasite in brain may be associated with chronic stages of infection (tissue cysts including bradyzoites, Dubey and Lindsay, 1996), and detection of Neospora DNA in lungs, liver and genital tract samples probably indicates invasion of these organs after parasitaemia. This study provides a follow-up of parasitaemia in heifers experimentally infected by $N$. caninum. The intermittent detection of Neospora DNA in blood may be due to small parasite numbers. Ho et al. (1996) and Ferre et al. (2005) reported intermittent detection of $N$. caninum in blood of experimentally and naturally 
infected cattle, respectively. However, several authors have pointed the difficulty to detect $N$. caninum in tissues and fluids in adult cattle, whether naturally or experimentally infected, because the low number of the parasite and their irregular distribution (De-Marez et al., 1999; Trees et al., 2002).

In our experiment, the inoculum consisted of a crude cell culture harvest containing free $N$. caninum tachyzoites mixed with bovine semen. The dose of tachyzoites chosen is similar to others used in experimental infections (Williams et al., 2000; Andrianarivo et al., 2001; Maley et al., 2001) and to show new routes of transmission (Uggla et al., 1998; De-Marez et al., 1999). The number of tachyzoites used to test the venereal route of infection could be higher than those previously found in seropositive bulls. We recently determined the parasite load in semen from five naturally infected, seropositive bulls and found a range of 1-10 tachyzoites/ml (mean 2.5) of semen (Ferre et al., 2005). However, the existence of higher $N$. caninum levels in bovine semen such as in acute infections needs to be determined. We nonetheless chosen the elevated tachyzoite dosage to confirm that this route of infection was feasible. It is thus also possible that parasites were enclosed in host cells such as mononuclear phagocytic cells. Our observations that most $N$. caninum DNA is found in the cell fraction, and virtually no specific DNA is present in seminal fluid supports this hypothesis (Ortega-Mora et al., 2003; Caetano-da-Silva et al., 2004; Ferre et al., 2005). In these conditions, tachyzoites might better resist passage through the genital tract than free tachyzoites, thereby retaining infectivity when reaching the uterine mucosa.

Our results suggest that $N$. caninum infection via semen at the dose used in this study affected embryonic development. Control group heifers showed a pregnancy rate $(66.6 \%)$ consistent with that observed in other primiparous heifers (about 60\%) of the same breed (Ormazabal et al., 1996), but the pregnancy rate of infected heifers was notably low $(11.1 \%)$. This effect could have several explanations. All heifers were similar in genetics and reproductive status and were managed in similar way (AI procedures, nutrition, hygiene and pen conditions), and the only difference between groups was the presence of $N$. caninum tachyzoites in semen. The first explanation at the low pregnancy rate in the inoculated heifers could be the infection and eventual death of the embryo. However, we failed to detect $N$. caninum DNA in the one recovered embryo and in vitro studies have shown that preimplantation stage bovine embryos are protected by the zona pellucida against Neospora invasion (Bielanski et al., 2002). Likewise, in the early stages of pregnancy, the tachyzoites included in semen may damage the uterus mucosa (inflammatory response to tachyzoite cell invasion) and prevent implantation or facilitate embryo expulsion. The detection of Neospora DNA in the uterine horn of two heifers may support this hypothesis. However, the data need to be interpreted with caution because hormonal and the local cellular immune responses could also affect implantation and embryo survival. Further studies should be carried out to clarify this question.

Several aspects of $N$. caninum epidemiology in cattle remain to be elucidated. An additional route of $N$. caninum transmission other than the transplacental route and sporulated oocyst intake can be presumed. Although this study provides evidence that horizontal transmission via contaminated semen is feasible in bovine neosporosis, further studies are underway to assess the minimum infectious dose and the parasite viability in semen, and whether venereal transmission has an important role in the spread of bovine neosporosis under natural conditions.

\section{Acknowledgements}

We are grateful to Vanesa Navarro, Inmaculada López, Rinaldo A. Mota, Esther Collantes, Argiñe Zubieta, Gloria Rubio and caretakers of "Finca La Mata", specially to José Luis Antón, for technical assistance. Funding for this work was provided by a research grant from the Spanish government (Pr950780.OP). Ignacio Ferre was financed by the Ramón y Cajal Spanish Scientific Pogramme. This work was also part of the EU research collaboration COST-854.

\section{References}

Andrianarivo, A.G., Barr, B.C., Anderson, M.L., Rowe, J.D., Packham, A.E., Sverlow, K.W., Conrad, P.A., 2001. Immune responses in pregnant cattle and bovine fetuses following experi- 
mental infection with Neospora caninum. Parasitol. Res. 87, $817-825$.

Bielanski, A., Robinson, J., Phipps-Todd, B., 2002. Effect of Neospora caninum on in vitro development of preimplantation stage bovine embryos and adherence to the zona pellucida. Vet. Rec. 150, 316-318.

Caetano-da-Silva, A., Ferre, I., Collantes-Fernández, E., Navarro, V., Aduriz, G., Ugarte-Garagalza, C., Ortega-Mora, L.M., 2004. Occasional detection of Neospora caninum DNA in frozen extended semen from naturally infected bulls. Theriogenology 62, 1329-1336.

Davison, H.C., Otter, A., Trees, A.J., 1999. Estimation of vertical and horizontal transmission parameters of Neospora caninum infections in dairy cattle. Int. J. Parasitol. 29, 1683-1689.

De-Marez, T., Liddell, S., Dubey, J.P., Jenkins, M.C., Gasbarre, L., 1999. Oral infection of calves with Neospora caninum oocysts from dogs: humoral and cellular immune responses. Int. J. Parasitol. 29, 1647-1657.

Dijkstra, Th., Barkema, H.W., Eysker, M., Wouda, W., 2001. Evidence of post-natal transmission of Neospora caninum in Dutch dairy herds. Int. J. Parasitol. 31, 209-215.

Dubey, J.P., 2003. Neosporosis in cattle. J. Parasitol. 89, S42-S56.

Dubey, J.P., Lindsay, D.S., 1996. A review of Neospora caninum and neosporosis. Vet. Parasitol. 67, 1-59.

Ferre, I., Aduriz, G., del-Pozo, I., Regidor-Cerrillo, J., Atxaerandio, R., Collantes-Fernández, E., Hurtado, A., Ugarte-Garagalza, C., Ortega-Mora, L.M., 2005. Detection of Neospora caninum in the semen and blood of naturally infected bulls. Theriogenology 63 , 1504-1518.

Gondim, L.F.P., McAllister, M.M., Pitt, W.C., Zemlicka, D.E., 2004. Coyotes (Canis latrans) are definitive hosts of Neospora caninum. Int. J. Parasitol. 34, 159-161.

Gondim, L.M., Gao, L., McAllister, M.M., 2002. Improved production of Neospora caninum oocysts, cyclical oral transmission between dogs and cattle, and in vitro isolation from oocysts. J. Parasitol. 88, 1159-1163.

Guy, C.S., Williams, D.J.L., Kelly, D.F., McGarry, J.W., Guy, F., Björkman, C., Smith, R.F., Trees, A.J., 2001. Neospora caninum in persistently infected pregnant cows: spontaneous transpla- cental infection is associated with an acute increase in maternal antibody. Vet. Rec. 149, 443-449.

Ho, M.S., Barr, B.C., Marsh, A.E., Anderson, M.L., Rowe, J.D., Tarantal, A.F., Hendrickx, A.G., Sverlow, K., Dubey, J.P., Conrad, P.A., 1996. Identification of bovine Neospora parasites by PCR amplification and specific small-subunit rRNA sequence probe hybridisation. J. Clin. Microbiol. 34, 1203-1208.

Innes, E.A., Andrianarivo, A.G., Björkman, C., Williams, D.J.L., Conrad, P.A., 2002. Immune responses to Neospora caninum and prospects for vaccination. Trends Parasitol. 18, 497-504.

Maley, S.W., Buxton, D., Thomson, K.M., Schriefer, E.S., Innes, E.A., 2001. Serological analysis of calves experimentally infected with Neospora caninum: a 1-year study. Vet. Parasitol. 96, 1-9.

McAllister, M.M., Dubey, J.P., Lindsay, D.S., Jolley, W.R., Wills, R.A., McGuire, A.M., 1998. Dogs are definitive hosts of Neospora caninum. Int. J. Parasitol. 28, 1473-1478.

Ormazabal, J.J., Osoro, K., Martínez, A., 1996. Efecto de los niveles de crecimiento y la presencia del toro en la edad a la pubertad de las novillas de raza Asturiana de los Valles. Investigación Agraria: Producción y Sanidad Animal 11, 201-214.

Ortega-Mora, L.M., Ferre, I., del-Pozo, I., Caetano-da-Silva, A., Collantes-Fernández, E., Regidor-Cerrillo, J., Ugarte-Garagalza, C., Aduriz, G., 2003. Detection of Neospora caninum in semen of bulls. Vet. Parasitol. 117, 301-308.

Paré, J., Thurmond, M.C., Hietala, S.K., 1996. Congenital Neospora caninum infection in dairy cattle and associated calfhood mortality. Can. J. Vet. Res. 60, 133-139.

Trees, A.J., McAllister, M.M., Guy, C.S., McGarry, J.W., Smith, R.F., Williams, D.J.L., 2002. Neospora caninum: oocyst challenge of pregnant cows. Vet. Parasitol. 109, 147-154.

Uggla, A., Stenlund, S., Holmdahl, O.J.M., Jakubek, E.-B., Thebo, P., Kindahl, H., Björkman, C., 1998. Oral Neospora caninum inoculation of neonatal calves. Int. J. Parasitol. 28, 1467-1472.

Williams, D.J.L., Guy, C.S., McGarry, J.W., Guy, F., Tasker, L., Smith, R.F., MacEachern, K., Cripps, P.J., Kelly, D.F., Trees, A.J., 2000. Neospora caninum-associated abortion in cattle: the time of experimentally-induced parasitaemia during gestation determines foetal survival. Parasitology 121, 347-358. 